$\mathrm{Oz}$

Volume 8

Article 16

$1-1-1986$

\title{
A Crematorium Complex: Manhattan, Kansas
}

\author{
Robert Bahan \\ Laurie Carron \\ David Hecht
}

See next page for additional authors

Follow this and additional works at: https://newprairiepress.org/oz

Part of the Architecture Commons

(c) $(1) \otimes(\theta)$

This work is licensed under a Creative Commons Attribution-Noncommercial-No Derivative Works 4.0 License.

\section{Recommended Citation}

Bahan, Robert; Carron, Laurie; Hecht, David; Masilionis, Matthew; and Miller, Rhonda (1986) "A

Crematorium Complex: Manhattan, Kansas," Oz: Vol. 8. https://doi.org/10.4148/2378-5853.1124

This Article is brought to you for free and open access by New Prairie Press. It has been accepted for inclusion in Oz by an authorized administrator of New Prairie Press. For more information, please contact cads@k-state.edu. 


\section{A Crematorium Complex: Manhattan, Kansas}

\section{Authors}

Robert Bahan, Laurie Carron, David Hecht, Matthew Masilionis, and Rhonda Miller 


\title{
A Crematorium Complex
}

\author{
Manhattan, Kansas
}

\author{
Robert Bahan \\ Laurie Carron \\ David Hecht \\ Matthew Masilionis \\ Rhonda Miller
}

Critic: William C. Miller

\begin{abstract}
"A crypt is generally taken as concealing a corpse. But in order to protect it from what? What is a corpse meant to be preserved intact from, if not, at one and the same time, from life and death, which could come upon it from the outside? And to make sure that death cannot have a place in life? Protection and exclusion are the features of every crypt and cemetery."
\end{abstract}

\section{-Maurizio Ferraris}

Today, a paucity of communicable design strategies or tactics exist for vitalizing the experiential and expressive relationship between built form and landscape. Landscape was not a primary concern of the Modern Movement except as a neutral green field upon which buildings were placed. As a neutral frame in either rural or urban contexts, landscape design became secondary to building design. Furthermore, the traditional experiential, aesthetic and symbolic dimensions accorded landscape design were reduced to utilitarian ones: gardens and parks were seen as obsolete, no longer viable in a modern world. If the Modern Movement had a bias towards the landscape, its preference was for the natural landscape rather than the designed landscape.

Of the major twentieth century architects, Sir Edwin Lutyens, Gunnar Asplund and Alvar Aalto provide some

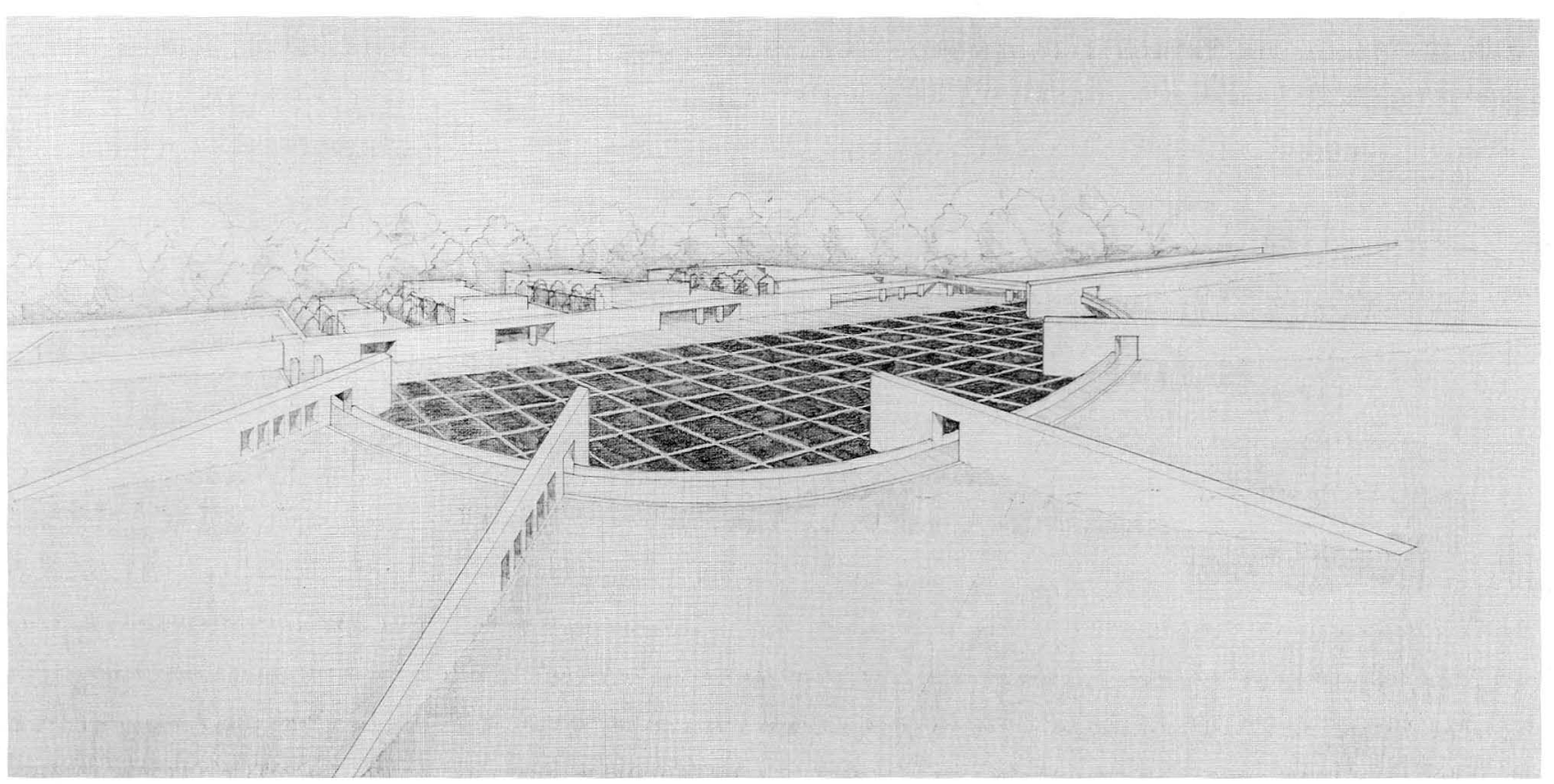

Perspective of chapels and columbarium, Matt Masilionis.

the design of the site or landscape. Their work demonstrates a concern with nature and landscape at three levels: first, a concern with the design of the larger landscape or setting; second, a concern for the integration of building and landscape which, of course, is not altogether inseparable from the first concern; and lastly, a concern for the incorporation of subsidiary architectural elements in the landscape.

In this design exercise the manipulation of buildings as objects in the landscape and how they support the ceremony of death and cremation become important issues. Specifically, in the solutions presented attention is given to the development of a defined design strategy addressing the relationship between building and the landscape.

Cremation of the human body has been and remains to be one of the significant means of ceremonially acknowledging human death. While cremation has become a conventional form of burial in Scandinavian countries, as well as elsewhere, it has only recently become accepted as an appropriate alternative to conventional burial in this country. Thus, while the design of a crematorium complex requires the normative organizational and technical skills of the architect, it further requires an especially sensitive understanding of our social and cultural attitudes. The design intention for the complex should establish an appropriate setting, or stage, for the specific and important nature of its function.

The site of the crematorium is within a residential neighborhood in Manhattan, Kansas, and is adjacent to an existing 


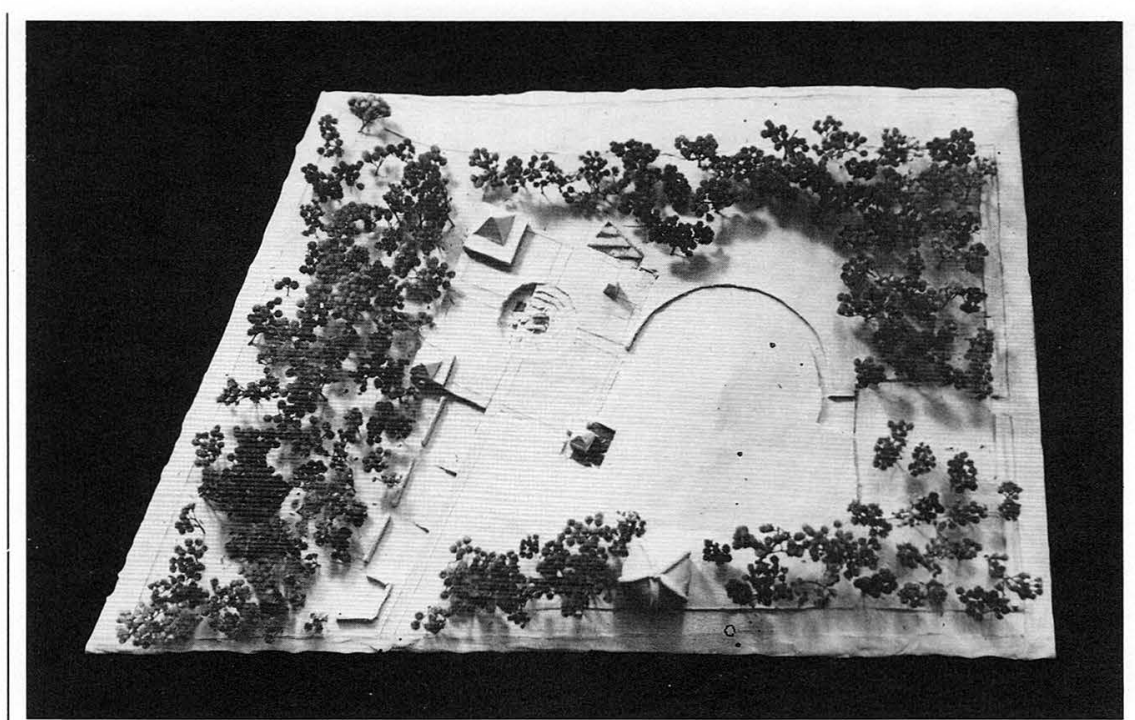

Model, David Hecht.

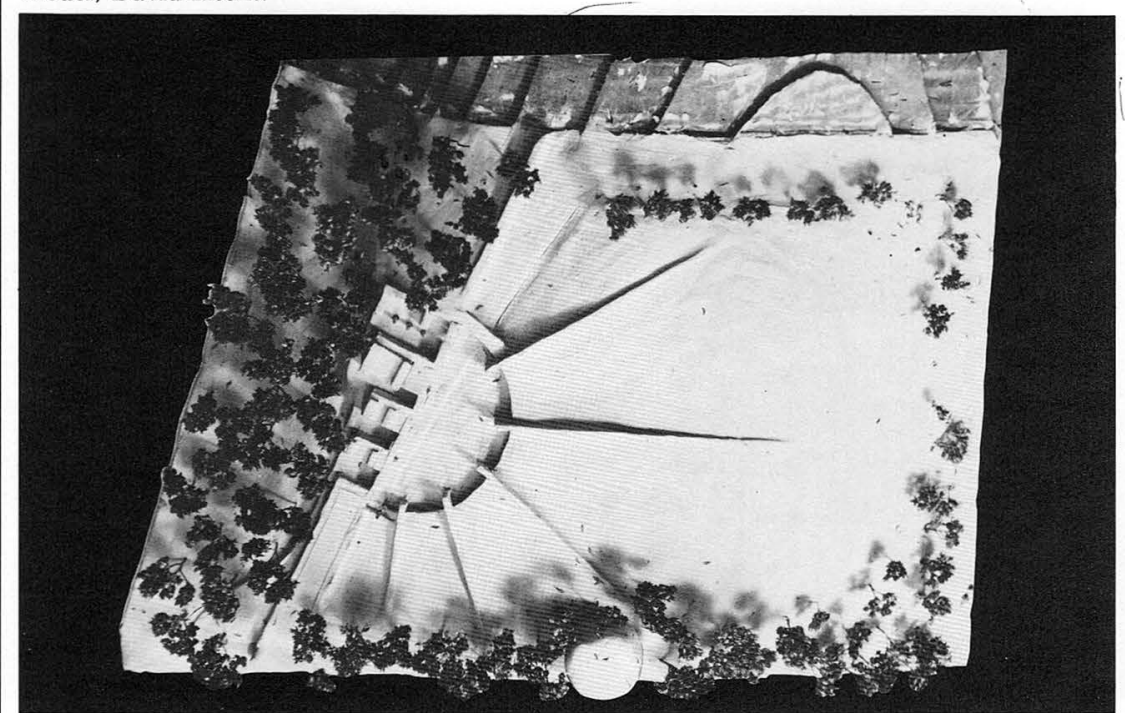

Model, Matt Masilionis.

cemetery. The site contains a hill slop ing gently upward from west to east. To the west is a dense grove of trees while on the south is Sunset Cemetery and an existing water tower.

The major elements included in this complex are: four chapels for funeral services; one each to house small, medium and large services and one exterior chapel which is to accommodate out door services in good weather; outdoor meditation spaces; and a columbarium to hold urns of ashes from cremation. The chapels are non-denominational and each requires a pre-service waiting area for the family, a coat room, a vestry for the clergy, and a committal court or space.

In addition to the compositional and ordering concerns of the crematorium complex, there is a recognition of the nuances accompanying the alliance between nature and architecture. These projects illustrate not only a division between public and private functions, but a division between the physical and the supernatural world. They are treated as sanctuaries in the landscape.

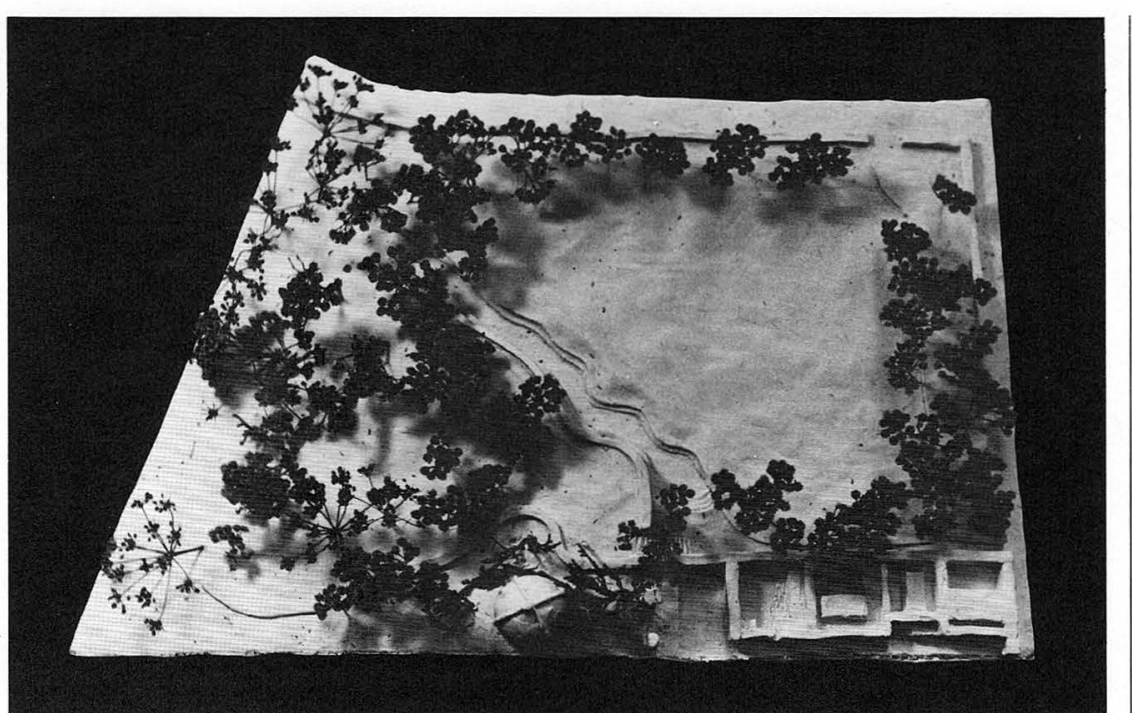

Model, Laurie Carron.

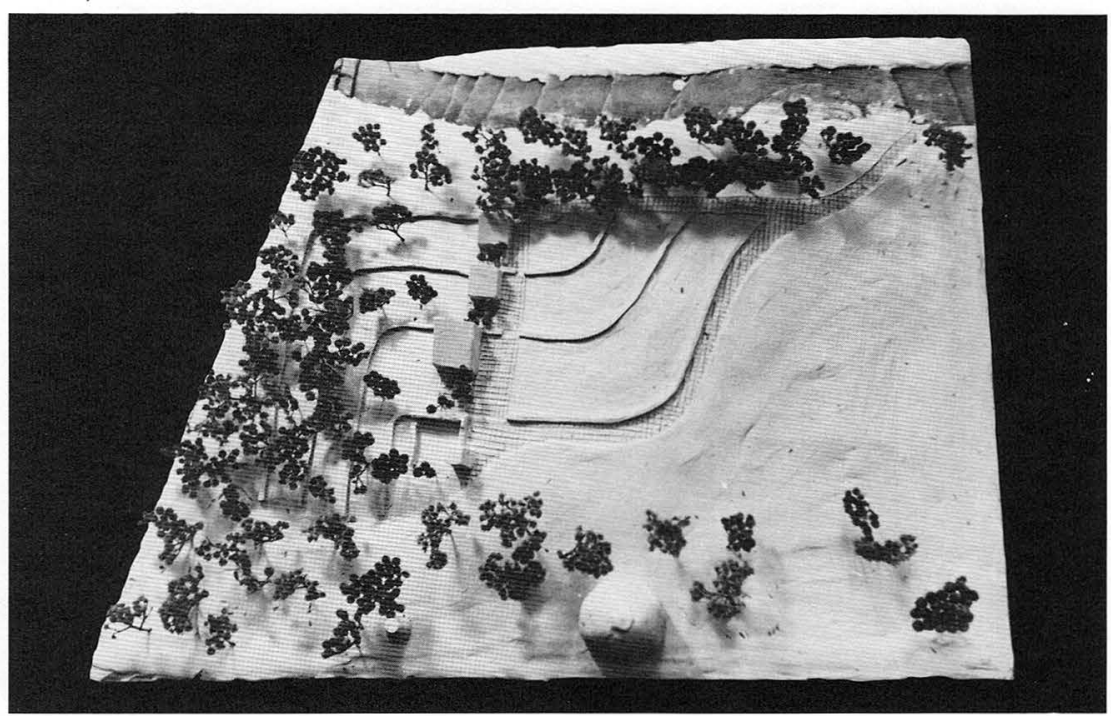

Model, Rhonda Miller.



Model, Robert Bahan. 